\section{Commentary: Epinephrine's meager benefit in resuscitation illustrates the need for shrewd bedside judgment when resuscitating cardiothoracic surgery patients}

\author{
Robin Varghese, MD, MS, FRCSC, and
} Parth Patel, BA

Epinephrine has been a staple of resuscitation efforts for decades. Most of the evidence for the use of epinephrine has been derived from animal studies followed by evidence in human subjects who sustained a cardiac arrest. ${ }^{1}$ However, concern for severe peripheral and central vasoconstriction of vital organs has raised some concerns over the harmful effects of epinephrine. ${ }^{2}$

In the Prehospital Assessment of the Role of Adrenaline: Measuring the Effectiveness of Drug Administration in Cardiac Arrest 2 (PARAMEDIC2) trial, ${ }^{3} 8014$ out-of-hospital cardiac arrest patients were assigned to receive either epinephrine or saline during resuscitation efforts. The unfortunate result of the trial was that despite having improved survival to 30 days in the epinephrine arm, this did not translate into an improved survival with a favorable neurological outcome when compared with placebo at hospital discharge $(1.18 \%$ in epinephrine group vs $1.19 \%$ in the placebo group).

In their review of this trial and how it applies to cardiothoracic surgery patients, Dunning and Trevis ${ }^{4}$ reference the Society of Thoracic Surgeons/European Association for Cardio-Thoracic Surgery guidelines for resuscitation

\footnotetext{
From the Department of Cardiovascular Surgery, Icahn School of Medicine at Mount Sinai, Mount Sinai Health System, New York, NY.

Disclosures: The authors reported no conflicts of interest.

The Journal policy requires editors and reviewers to disclose conflicts of interest and to decline handling or reviewing manuscripts for which they may have a conflict of interest. The editors and reviewers of this article have no conflicts of interest.

Received for publication June 11, 2020; accepted for publication June 11, 2020; available ahead of print June 29, 2020.

Address for reprints: Robin Varghese, MD, MS, FRCSC, Department of Cardiovascular Surgery, Icahn School of Medicine at Mount Sinai, Mount Sinai Health System, New York, NY 10029 (E-mail: robin.varghese@mountsinai.org).

J Thorac Cardiovasc Surg 2020;160:1523-4 $0022-5223 / \$ 36.00$

Copyright (c) 2020 Published by Elsevier Inc. on behalf of The American Association for Thoracic Surgery

https://doi.org/10.1016/j.jtcvs.2020.06.065
}

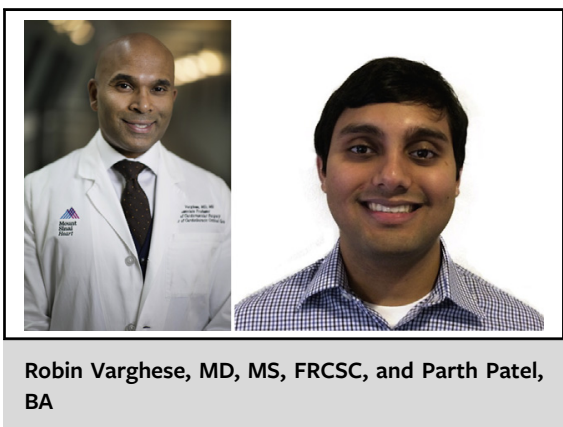

CENTRAL MESSAGE

In a double-blind, placebocontrolled trial, the use of epinephrine during out-ofhospital cardiac arrest improved survival to 30 days but did not improve survival to discharge with a favorable neurological outcome.

for cardiac arrest after cardiac surgery. It must be stated that the results of the PARAMEDIC2 trial have very little to do with an in-hospital cardiac arrest. The authors point out the mean time to the administration of epinephrine was 19 minutes. In addition, the quality of bystander cardiopulmonary resuscitation (CPR) is also uncertain. Both of these likely contributing to the poor neurological outcomes seen. It goes without saying that in a cardiac surgery intensive care unit the time to the first epinephrine dose would be less than 3 minutes and the quality of CPR can be measured using a variety of metrics readily available.

The authors discuss the potential causes for a cardiac arrest after cardiac surgery. In these settings, the guidelines for resuscitation for cardiac arrest after cardiac surgery do not recommend routine immediate administration of $1 \mathrm{mg}$ epinephrine as a bolus. ${ }^{4}$ Although it may be helpful in raising blood pressure, a $1 \mathrm{mg}$ epinephrine bolus can also lead to uncontrollable hemorrhage from fresh aortic suture lines being exposed to extreme blood pressures. Therefore the focus should be on the acute reversible causes while CPR is initiated. In addition, this author supports a senior clinician considering smaller doses of epinephrine during CPR in postoperative cardiac surgery patients to assess the patient's blood pressure response.

The authors of the review state "the PARAMEDIC2 trial strongly confirms our belief that epinephrine will 
be of no benefit to our patients." ${ }^{4}$ This statement is really quite contrary to studies that have shown that the time to administration of epinephrine during inhospital cardiac arrest in nonshockable rhythms affects survival with favorable neurological outcomes. Caution should be taken in postoperative cardiac surgery patients. $^{5}$

The PARAMEDIC2 trial provides little evidence of the value epinephrine during in-hospital cardiac arrest, particularly after cardiac surgery. The authors make a good argument that epinephrine should not be bolused indiscriminately in postoperative cardiac surgery patients who experience cardiac arrest. Indeed there may exist a number of quick reversible causes that should be the focus of the medical team while CPR is initiated, and preparations for emergency chest reopening are undertaken.

\section{References}

1. Paradis NA, Martin GB, Rivers EP, Goetting MG, Appleton TJ, Feingold M, et al. Coronary perfusion pressure and the return of spontaneous circulation in human cardiopulmonary resuscitation. JAMA. 1990;263:1106-13.

2. Loomba RS, Nijhawan K, Aggarwal S, Arora RR. Increased return of spontaneous circulation at the expense of neurologic outcomes: is prehospital epinephrine for out-of-hospital cardiac arrest really worth it? J Crit Care. 2015;30:1376-81.

3. Perkins GD, Ji C, Deakin CD, Quinn T, Nolan JP, Scomparin C, et al. A randomized trial of epinephrine in out-of-hospital cardiac arrest. $N$ Engl J Med. 2018;379: 711-21.

4. Dunning J, Trevis J. Results of the PARAMEDIC-2 trial and how they relate to resuscitation after cardiac surgery. J Thorac Cardiovasc Surg. 2020;160:1519-22.

5. Donnino MW, Salciccioli JD, Howell MD, Cocchi MN, Giberson B, Berg K, et al. Time to administration of epinephrine and outcome after in-hospital cardiac arrest with non-shockable rhythms. BMJ. 2014;20:1-9.
See Article page 1519.

\section{Commentary: To epi or not to epi- that is the question}

\author{
Nabeel H. Gul, MD, and Subhasis Chatterjee, MD
}

When evidence is not clear, perception can obscure reality. Epinephrine has been widely used in resuscitation after cardiac arrest; however, its role in improving long-term survival with a favorable neurologic outcome is questionable. In a review of the multicenter 2018 Prehospital Assessment of the Role of Adrenaline: Measuring the Effectiveness of Drug Administration in Cardiac Arrest (PARAMEDIC-2) trial, ${ }^{1}$ Dunning and Trevis ${ }^{2}$ ask in this issue of Journal whether the trial results can be extrapolated to postcardiotomy arrest.

The critical distinction is that the PARAMEDIC-2 trial focused exclusively on out-of-hospital cardiac arrest (OHCA); postcardiotomy arrest, in contrast, is an inhospital cardiac arrest (IHCA). The all-comer survival

From the Division of General and Cardiothoracic Surgery, Michael E. DeBakey Department of Surgery, Baylor College Medicine; and Department of Cardiovascular Surgery, Texas Heart Institute, Houston, Tex.

Disclosures: Authors have nothing to disclose with regard to commercial support.

Received for publication March 23, 2020; revisions received March 23, 2020; accepted for publication March 24, 2020; available ahead of print April 10, 2020.

Address for reprints: Subhasis Chatterjee, MD, Baylor College of Medicine, One Baylor Plaza, MS: BCM 390, Houston, TX 77030-3411 (E-mail: subhasis. chatterjee@bcm.edu).

J Thorac Cardiovasc Surg 2020;160:1524-5

$0022-5223 / \$ 36.00$

Copyright (c) 2020 by The American Association for Thoracic Surgery

https://doi.org/10.1016/j.jtcvs.2020.03.098
Check for updates

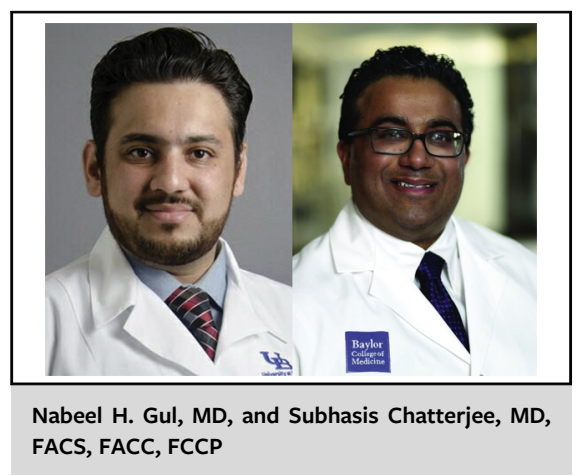

CENTRAL MESSAGE

Standard resuscitation measures

after postcardiotomy cardiac ar-

rest require thoughtful consid-

eration. Epinephrine should be

used cautiously but not

abandoned.

rate after IHCA is approximately $25 \%$, compared with $10 \%$ to $12 \%$ for OHCA, because IHCA is characterized by rapid initiation of basic life support and resuscitation medications in contrast to the 20 minutes seen in the PARAMEDIC-2 trial. $^{3}$ This is even more pronounced when results are compared across hospitals, with IHCA survival rates ranging from $8 \%$ to $31 \% .{ }^{4}$ Differences in cardiopulmonary resuscitation (CPR) quality or postarrest 